\title{
A Rare Case of Metachronous Bilateral Angiosarcoma of the Breast
}

\author{
Sheng-Ang Zhou ${ }^{a, b}$ Hongquan Weic Kefeng Ding ${ }^{a}$ \\ ${ }^{a}$ Department of Surgical Oncology, Education Ministry Key Laboratory of Cancer Prevention and Intervention, \\ Second Affiliated Hospital of Zhejiang University School of Medicine, \\ ${ }^{\mathrm{b}}$ Zhejiang Provincial People's Hospital, \\ ' Department of Pathology, Education Ministry Key Laboratory of Cancer Prevention and Intervention, \\ Second Affiliated Hospital of Zhejiang University School of Medicine, China
}

\section{Key Words}

Breast angiosarcoma - Primary angiosarcoma .

Bilateral · Breast sarcoma

\section{Summary}

Background: Primary angiosarcoma of the breast (PAB) is a rare occurrence of highly aggressive biological behavior. Bilateral PAB is even more infrequent. Case Report: We present the case of a 39-year-old Chinese woman with metachronous bilateral PAB (2005 and 2008). The diagnosis of PAB was confirmed. The respective masses were removed via simple mastectomy. The extent of malignancy differed microscopically between the two tumors and indicated a different source. After two surgeries and a 3-year follow-up, the patient is alive and well. The current case illustrates an unusual presentation of this rare type of breast sarcoma, in that none of the clinicopathological findings are thought to confer a good prognosis. We also review the literature and summarize relevant findings concerning definition, pathology, clinical features, treatment, and follow-up. Conclusions: We believe that the survival rate depends on tumor size and differentiation. Surgical resection followed by chemotherapy may prove to be effective and afford the best prognosis in the future.

\section{Introduction}

Primary angiosarcoma of the breast $(\mathrm{PAB})$ is a rare type of breast sarcoma of highly aggressive biological behavior. It accounts for less than $0.05 \%$ of all breast malignancies $[1,2]$.

\author{
Schlüsselwörter \\ Angiosarkom der Brust . Primäres Angiosarkom . \\ Bilateral · Mammasarkom
}

\section{Zusammenfassung}

Hintergrund: Das primäre Angiosarkom der Brust (PAB) ist eine seltene Erkrankung gekennzeichnet von hochaggressivem biologischen Verhalten. Bilaterale PAB sind noch seltener. Fallbericht: Wir berichten von einer 39-jährigen Chinesin mit metachronem bilateralen PAB (2005 und 2008). Nach Bestätigung der PAB-Diagnose wurden die jeweiligen Tumoren durch einfache Mastektomie entfernt. Das mikroskopische Ausmaß der Malignität der beiden Tumoren war unterschiedlich und wies auf einen uneinheitlichen Ursprung hin. Nach zwei Operationen und einem 3-jährigen Follow-up ist die Patientin in gutem gesundheitlichen Zustand. Der vorliegende Fall stellt eine ungewöhnliche Präsentation dieser selten Form des Mammasarkoms dar, da keiner der kinikopathologischen Befunde mit einer guten Prognose assoziiert ist. Des Weiteren geben wir einen Überblick über die Literatur und fassen relevante Erkenntnisse bezüglich Definition, $\mathrm{Pa}$ thologie, klinischen Eigenschaften, Behandlung und Follow-up zusammen. Schlussfolgerung: Wir glauben, dass die Überlebensrate von der Größe und dem Differenzierungsgrad der Tumoren abhängt. Chirurgische Resektion gefolgt von Chemotherapie könnte sich als effektiv erweisen und zukünftig die beste Prognose gewähren.

The 3-year disease-free survival (DFS) and overall survival (OS) of PAB are 14 and 38\%, respectively [3]. Bilateral occurrence is extremely rare, and metacronous bilateral occurrence has never been reported up until now. We present the case of a 36-year-old woman with metachronous bilateral PAB,

\section{KARGER}

Fax +497614520714

Information@Karger.de

www.karger.com (c) 2009 S. Karger GmbH, Freiburg

Accessible online at:

www.karger.com/brc
Dr. Kefeng Ding

Department of Surgical Oncology

Second Affiliated Hospital of Zhejiang, University School of Medicine

Jiefang Road 88\#, Hangzhou, Zhejiang Province, 310009, China

Tel. +86 571 8778-4719, Fax. -3458

dingkefeng@zju.edu.cn 
who after two surgeries continues to be in good health. The rarity and poor prognosis of this disease, especially its metachronous occurrence in both breasts, drew our attention. We describe the features of bilateral $\mathrm{PAB}$ and review the relevant literature. We believe that it is of great importance to report every occurring case of this rare tumor entity in order to pool as much information as possible on its biology.

\section{Case Report}

In June 2005, a 36-year-old premenopausal Chinese woman consulted us after noticing gradual enlargement of a tumor below her right nipple over a 1 -year period, causing mild pain. She had 1 child, born by Caesarean section. On examination, there was a tender, mobile lump about $3.0 \times 3.0 \mathrm{~cm}$ in size, without axillary lymph node enlargement. Ultrasound revealed an area of hypoechoic heterogeneity. Infrared thermography showed blocks of calescence in the right breast. No detectable metastatic disease was found. The entire lesion was removed. Microscopically, the tumor was considered to be an angiosarcoma. A simple mastectomy followed. Besides, a suspicious axillary lymph node was removed, and pathological findings were negative. Histopathological examination confirmed the diagnosis of PAB (figs. 1 and 2). Immunohistochemistry revealed the tumor cells to be positive for CD34(+++), Vim(+++), Ki67(+), and Factor VIII(+), and negative for SMA, EMA, CD68, and CKP, indicating an endothelial genesis.

Two years later, the patient noted a coffee bean-like, slightly tender, nodule near the left nipple. By July 2008, the lump had transformed to a movable 'walnut'. The examination result was similar to the previous time. After a lumpectomy, pathology confirmed a malignant tumor, and the patient was treated with simple mastectomy. Macroscopically, the cut surface of the specimen showed a $2.5-\mathrm{cm}$ hemorrhagic lesion within the breast proper. Microscopically, the lesion was composed of intricate vascular channels surrounding and invading the breast lobules. Most of the neoplastic cells were well differentiated angiosarcoma cells (fig. 3). The vascular channels were lined by cells with pleomorphic vesicular nuclei, which also infiltrated the lobules. Numerous mitoses were noted. There was endothelial tufting and solid sarcomatous appearance in areas without necrosis. Immunohistochemistry showed the tumor cells to be positive for CD31(+++), CD34(+++), CD99(+++), p53(+), Ki67(+, 10\%), and Factor $\operatorname{VIII}(+++)$, and negative for CK (AE1/AE3), confirming the endothelial genesis. The final diagnosis was PAB, histological grade 2 (Donnell's II).

After having undergone two surgeries in 3 years, the patient continues to be in good health with no signs of metastasis. The two tumors manifested similarities in size, course, and pathologic grading, but nevertheless differed somewhat in terms of the malignancy of the pathological features. Microscopically, nearly $20 \%$ of tumor cells were poorly differentiated in the first tumor (June 2005) while this was the case in only about $5 \%$ of cells in the second tumor (July 2008). This different extent of malignancy between the two tumors indicated a different source. That visible diversity of the pathological features based on the asynchronism is the reason why we believe this case to be distinguished from the other 1 or 2 reported cases of bilateral $\mathrm{PAB}$ which had occurred simultaneously.

\section{Discussion}

Chen et al. [3] found that the pathological appearance of initial PAB tumors is roughly the same as that of following ones, but metastatic lesions are much more malignant. So PAB is considered as multifocal. Well-differentiated bilateral PAB could both be considered as primary unless metastasis is de-
Fig. 1. Tissue poorly differentiated and composed of allotypic cells; numerous mitoses were noted $(\mathrm{H} \& \mathrm{E} \times 200)$.

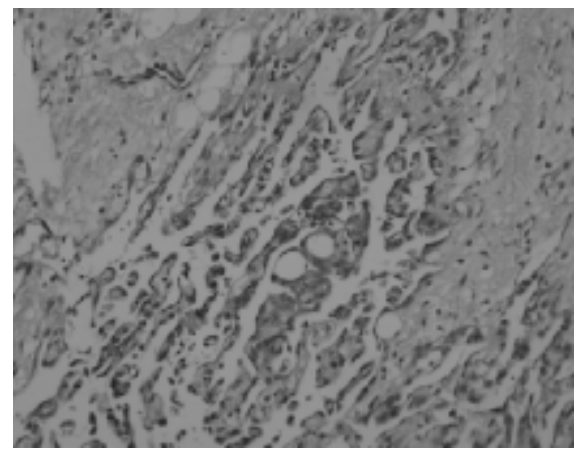

Fig. 2. There were solid sarcomatous areas but no areas of necrosis $(H \& E \times 200)$.

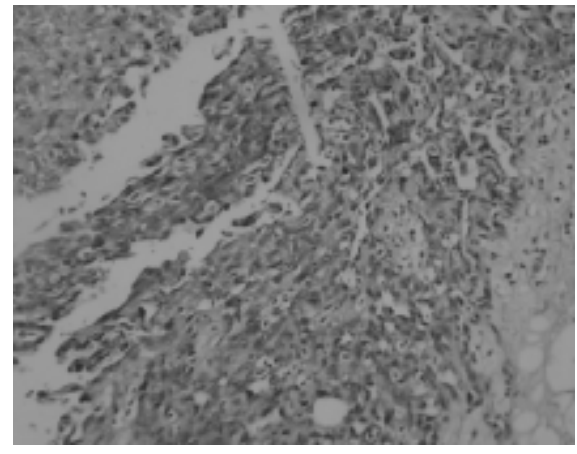

Fig. 3. Well-differentiated angiosarcoma cells infiltrating the residual breast acini which are themselves normal $(H \& E \times 200)$.

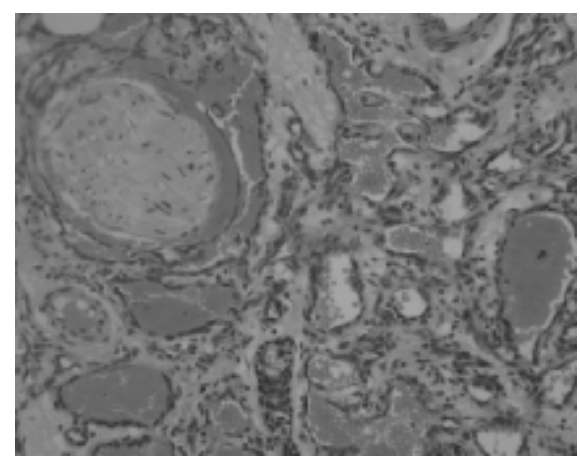

tected. Therefore, in this case, due to the dissimilar malignancy, both tumors are thought to be primary. To the best of our knowledge, this is the first case of metachronous bilateral PAB to ever have been reported.

The age and clinical appearance of our patient is in concordance with other cases reported in the literature. In Donnell et al.'s [1] series of 40 cases of PAB, the age at presentation ranged from 16 to 69 years, with a mean of 34 years. The manner of presentation was usually a mobile, painless, well-circumscribed mass which clinically felt like either a carcinoma or benign breast disease. Occasionally, cases presented as a bulky hemorrhagic mass, with even purple discoloration of the skin, suggesting a vascular neoplasm. It should be mentioned that another type of angiosarcoma of the breast - secondary angiosarcoma arising from radiotherapy - tends to involve the skin, and its typical simultaneous symptom is edema of the upper extremity (Stewart-Treves syndrome) $[2,4]$. By definition, PAB does not have any such antecedent. Microscopically, PAB cells root in the parenchymatous tissue which is deeper, however, angiosarcoma cells caused 
by radiotherapy tend to concentrate in the dermis. This also suggests two different types of tumor. Angiosarcoma is associated with a poor prognosis, and most patients die shortly after diagnosis. Metastatic angiosarcoma of the lung, skin, maxillary gingiva, liver, bone, spleen, ovary, etc. have been reported in the literatures [5]. The reported 3-year OS is 38\%, and 3 -year DFS only $14 \%$ [4]. Fortunately, our patient is well with no evidence of metastasis, and may have a good chance to live longer. Tumor size and grading of differentiation are thought to be the most important prognostic factors. But in the recent literature, Nascimento et al. [6] considered there to be no correlation between histological grade and patient outcome, which is in line with angiosarcoma at other sites.

It is necessary to perform a surgical biopsy and immunohistochemistry to establish the diagnosis of PAB. However, an accurate preoperative diagnosis may be difficult, even with the aid of fine-needle aspiration cytology and biopsy. Both mammogram and ultrasound tend to be nonspecific, like with ill-defined masses or skin thickening. Although macroscopically the tumor is well circumscribed, there may be foci of invasion in the surrounding breast tissue composed of intricate vascular channels surrounding and invading breast lobules. Ultrastructural examination of the cells may show intermediate filaments, for example, vimentin, cytokeratin, and WeibelPalade bodies. And pinocytic vesicles are connected in some cases. Immunostaining for factor VIII-related antigen is confirmatory for PAB. CD31 and CD34 tend to be positive, with similar sensitivity, but different specificity [7]. Despite the low number of PAB cases, Gennaro et al. [8] found in their series that vascular endothelial growth factor receptor (VEGF-R) expression is highly related to low- and intermediate-grade tumors and may play a role in predicting a particular patient's clinical course. In their finding, VEGF-R was positive in $64 \%$ of cases which were associated with low- and intermediategrade tumors $(\mathrm{p}$ value $=0.0030)$. However, the sensitivity of VEGF-R expression is yet to be established.

Surgery is still considered the most applicable approach. Axillary lymph node dissection is not essential in the man- agement of this tumor which characteristically transfers via hematogenous spread, and hardly via the lymph nodes. We support wide local excision as the best treatment, followed by adjuvant therapy (chemotherapy, radiation) if there are microscopically involved margins. Silverman et al. [9] noted the statistical superiority of adjuvant chemotherapy to the more poorly differentiated tumors $(29.2$ vs. $4.4 \%$; $<<0.05)$. In the present case, the patient received simple mastectomy of the right breast in 2005, and of the left breast in 2008. We did not recommend postoperative therapy. However, we take great interest in docetaxel to which PAB shows major response. Chemotherapy based on docetaxel and radiation should be considered if the tumor infiltrates the skin or thoracic cavity [10]. Some authors propose that if negative surgical margins can be achieved, breast sarcoma should be managed by conservative surgery with postoperative irradiation to a microscopic tumoricidal dose (50 Gy) to the whole breast, and at least $60 \mathrm{~Gy}$ to the tumor bed. $\alpha$-TNF and $\alpha$-INF have been adopted in adjuvant therapy and showed an efficacy of about $84 \%$; however, this would need to be verified. Despite of what is mentioned above, Gennaro et al. [8] suggest the use of a targeted therapy in the adjuvant setting when VEGF-R is expressed. We expect new individual cases to be reported which can be controlled effectively.

In summary, painless breast tumors in young women, that are highly vascular at the time of biopsy should be considered as malignant until proven otherwise. Although PAB generally have a poor prognosis, a few cases, including some bilateral $\mathrm{PAB}$, may obtain a good chance for longer survival. We think that the survival rate depends on tumor size and tumor differentiation. Surgical resection followed by adjuvant approaches may prove to be effective in the future and afford the best prognosis.

\section{Conflict of Interest}

The authors confirm that there was no conflict of interest.

\section{References}

1 Donnell RM, Rosen PP, Lieberman PH, Kaufman RJ, Kay S, Braun DW, Kinne DW: Angiosarcoma and other vascular tumors of the breast. Am J Surg Path 1981;5:629-642.

2 Luini A, Gatti G, Diaz J, Botteri E, Oliveira E, Cecilio Sahium de Almeida R, Veronesi P, Intra, M, Pagani G, Naninato P, Viale G: Angiosarcoma of the breast: the experience of the European Institute of Oncology and a review of the literature. Breast Cancer Res Treat 2007;105:81-85.

$\checkmark 3$ Chen KT, Kirkegaard DD, Bocian JJ: Angiosarcoma of the breast. Cancer 1980;46:368-371.
4 Fernández Ortega A, Gil Gil JM, Urruticoetxea A, Serra Payró, JM: Angiosarcoma of the breast. Two cases following breast conserving treatment for invasive carcinoma. Clin Transl Oncol 2006;8:536-539.

$\checkmark 5$ Tiwary SK, Singh MK, Prasad R, Sharma D, Kumar M, Shukla VK: Primary angiosarcoma of the breast. Surgery 2007;141:821-822.

6 Nascimento AF, Raut CP, Fletcher CD: Primary angiosarcoma of the breast: clinicopathologic analysis of 49 cases, suggesting that grade is not prognostic. Am J Surg Pathol 2008;32:1896-1904.

7 Ohsawa M, Naka N, Tomita Y, Kawamori D, Kanno H, Aozasa K: Use of immunohistochemical procedures in diagnosing angiosarcoma. Evaluation of 98 cases. Cancer 1995;75:2867-2874.
8 Gennaro M, Valeri B, Casalini P, Carcangiu ML, Gronchi A, Conti AR, Ferraris C, Giovanazzi R, Greco M: Angiosarcoma of the breast and VEGF-R expression. Eur J Cancer 2008;6(suppl):185-185.

9 Silverman LR, Deligdisch L, Mandeli J, Greenspan EM: Chemotherapy for angiosarcoma of the breast: case report of 30 year survival and analysis of the literature. Cancer Invest;1994;12:145-155.

10 Mano MS, Fraser G, Kerr J, Gray M, Evans V, Kazmi A, Canney P: Radiation-induced angiosarcoma of the breast shows major response to docetaxel after failure of anthracycline-based chemotherapy. Breast;2006;15:117-118. 